\title{
One-step fabrication of high refractive index inorganic nanostructures
}

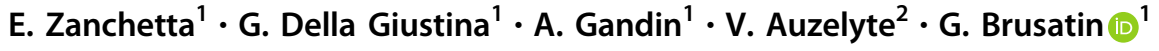

Received: 5 April 2021 / Accepted: 11 August 2021

(C) The Author(s) 2021

\begin{abstract}
Direct printing of spin-on functional films is probably the most efficient method to develop low-cost novel photonic nanodevices, such as diffraction gratings, planar waveguides, nano- lasers, and antireflective coatings. For these applications high refractive index transparent materials are demanded; however, this class of materials generally requires inorganic oxides, well known for their hardness, typical of ceramic materials, and so incompatible with a soft character of printable resins. Herein, inorganic high refractive index $\mathrm{TiO}_{2}$ micro- and nano- structures, with unusual depth up to $600 \mathrm{~nm}$ and aspect ratio larger than 5 , are obtained by combining thermal nanoimprint lithography (NIL) with UV curing. To achieve printed patterns, a hybrid organic-inorganic spin-on film is deposited at low-temperature by sol-gel processing. Two distinct bottomup synthetic approaches are used, called in situ and ex situ, using titanium isopropoxide (90\%) or $\mathrm{TiO}_{2}$ anatase nanoparticles (70\%), respectively, and adding a silica sol modified by organic moieties. The two syntheses were optimized to obtain, after patterning by thermal imprint, amorphous or crystalline titania crack-free micro- and nano- patterns for in situ and ex situ, respectively. The further UV irradiation converts imprinted films to totally inorganic patterns, through the titania photocatalytic effect, allowing refractive indexes up to 1.82 at $632 \mathrm{~nm}$ to be achieved. This novel strategy of combining thermal imprint with UV exposure allows inorganic deep patterns to be fabricated without a calcination step, which is generally needed for inorganic resists processing. Eventually, a thermal treatment only at $300{ }^{\circ} \mathrm{C}$ can be applied to achieve a final refractive index of 2 at $632 \mathrm{~nm}$.
\end{abstract}

\section{Graphical Abstract}

Direct printing of spin-on $\mathrm{TiO}_{2}$ high refractive index $(1.82 @ 632 \mathrm{~nm}$ ) transparent films, with depth up to $600 \mathrm{~nm}$, aspect ratio larger than 5 and without lateral shrinkage are obtained combining thermal Nanoimprint Lithography (NIL) with UV curing.
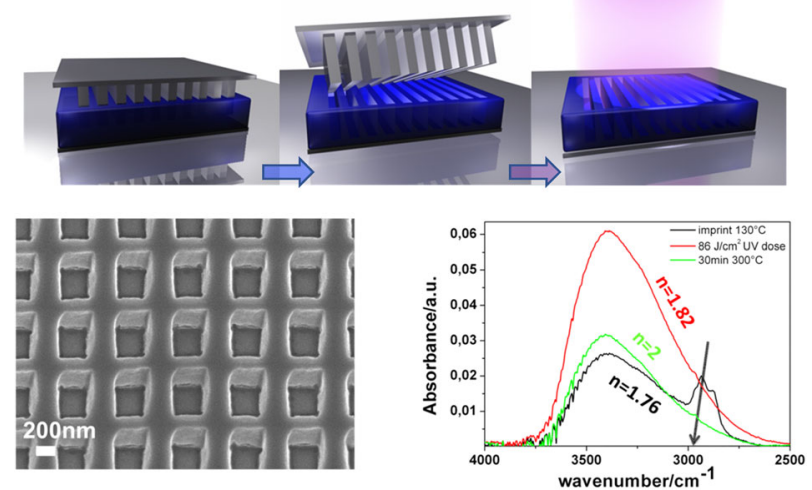

G. Brusatin

giovanna.brusatin@unipd.it

1 Industrial Engineering Department and INSTM, Via Marzolo 9, 35131 Padova, Italy 
Keywords Nano-imprinting $\cdot$ Resist $\cdot$ Sol-gel $\cdot$ Hybrid organic-inorganic $\cdot \mathrm{TiO}_{2}$

\section{Highlights}

- A simple straightforward one-step surface patterning process by NIL technology of high refractive index $\mathrm{TiO}_{2}$ systems is proposed.

- The hybrid nature of films combines the required intrinsic properties of inorganic titania and the simple processing of organic resists.

- Micro- and nano-inorganic structures up to $600 \mathrm{~nm}$ deep and refractive index up to 2 at $632 \mathrm{~nm}$ are achieved.

\section{Introduction}

Optical nanostructures, from diffraction gratings and waveguides to advanced geometries for light manipulation such as photonic crystals, have increased demands for development and applications. In particular, high refractive index materials and their patterning have acquired more and more importance in application ranging from ophthalmic lenses, filters, optical adhesives, highly reflective and antireflection coatings as well as advanced optoelectronic fabrications [1-9].

Titania, $\mathrm{TiO}_{2}$, is certainly one of the most studied materials. However, it is conventionally patterned by liftoff $[10,11]$, a process that does not work well when thick films (some hundreds of $\mathrm{nm}$ ) or complex patterns are needed. Other methods make use of different material templates or SAMs [12-17], allowing titania structures to be obtained by means of a sacrificial pattern acting as template that needs to be eliminated through hightemperature thermal treatment.

Some direct patterning techniques, such as electron beam, AFM, two-photon lithography and electrohydrodynamic patterning, have then been used to obtain titanium oxides patterns [18-22]. However, these are mostly non-scalable imprinting processes.

Recently, much effort has been directed towards nanoimprint lithography (NIL) to obtain inorganic structures, since NIL is a low-cost, high throughput and highresolution processes, presenting a potential industrial impact in the production of optical micro- and nanosystems

[23-26], as was recently demonstrated for example by ultrafast nanoimprinting and roll-to-roll imprinting techniques. Few resists are generally available for NIL, but sol-gel methods enable spin-on inorganic film compositions suitable for NIL to be developed if properly designed and engineered. In fact, the few examples in the literature of direct imprint of inorganic $\mathrm{TiO}_{2}$ systems reveal that some major challenges have to be faced when working with sol-gel compounds: (1) sol-gel films have high surface energy, causing mold release problems; (2) the solvent or organic moieties (chelating or coordinating agents) that help to 'soften' the material generally get trapped in the imprinted structures; and (3) sol-gel materials do not have a workable softening point, generally exhibiting a thermosetting behavior. As a consequence, inorganic titania patterned films obtained either by thermal (T-NIL) or UV assisted (UV-NIL) imprint, suffer from the following limits: (1) only shallow patterns, less than $100 \mathrm{~nm}$ [27, 28], can be obtained without crack formation; (2) only films with low titania content can be patterned [23, 29, 30]; (3) high shrinkages occur during processing up to $75 \%$ [3133]; and (4) refractive index up to 1.98 at $632 \mathrm{~nm}$ [34] can be achieved only after annealing at $500{ }^{\circ} \mathrm{C}$.

Soft lithography [35] helped to overcome these problems, since PDMS [36-38] and PFPE [36] soft molds, in contrast to the rigid stamps used in NIL, have low surface energies and a permeable nature that absorbs solvents typically used in sol-gel processing; nevertheless, this technique presents mold deformation problems, such as high shrinkages, and shallow structures, in particular, when sub-100-nm features are desired [39].

Herein, we propose a simple straightforward one-step patterning process of two transparent spin-on hybrid $\mathrm{TiO}_{2}$ resists from wet chemistry (named in situ and ex situ) using T-NIL followed by UV curing. Both materials and processes benefit from several possible advantages. First, two different syntheses strategies (schematized in Fig. 1) are followed to obtain inorganic imprinted structures, i.e., using a Ti-precursor (in situ) or commercial anatase nanoparticles (ex situ), giving different final crystalline structures. Second, the hybrid nature of both films combines the required intrinsic properties of inorganic titania (e.g., high refractive index, up to 1.82 at $632 \mathrm{~nm}$ ) and the simple processing of organic resists, which allows initially soft films to be easily imprinted and produces up to $600 \mathrm{~nm}$ deep micro- and nano- inorganic structures. Third, the composition and final refractive index of the patterned features can be easily tailored at room temperature through UV exposure, exploiting the photocatalytic activity of $\mathrm{TiO}_{2}$. The overall imprinting process is schematized in Fig. 2. Finally, refractive index up to 2 at $632 \mathrm{~nm}$ can be eventually obtained with a $300{ }^{\circ} \mathrm{C}$ treatment if required for specific applications. 
Fig. 1 Precursor alkoxides (TiOPr, GPTMS) and nanoparticles $\left(\mathrm{TiO}_{2}\right.$ dispersion, $15 \mathrm{~nm}$ ) used in the $\mathrm{TiO}_{2}$ synthesis. The main component of the in situ and ex situ sol compositions derives from TiOPr and $\mathrm{TiO}_{2}$ nanoparticles, respectively

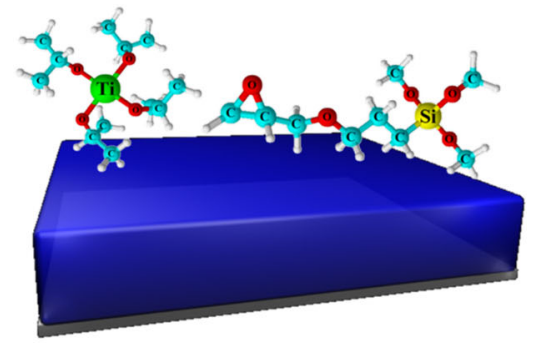

IN SITU

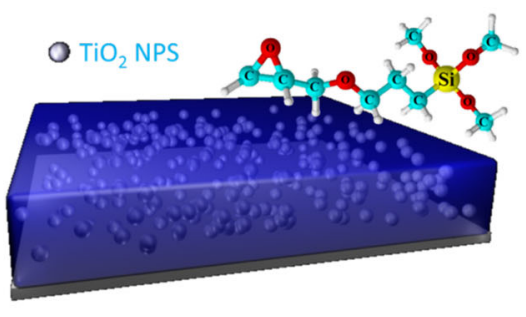

EX SITU
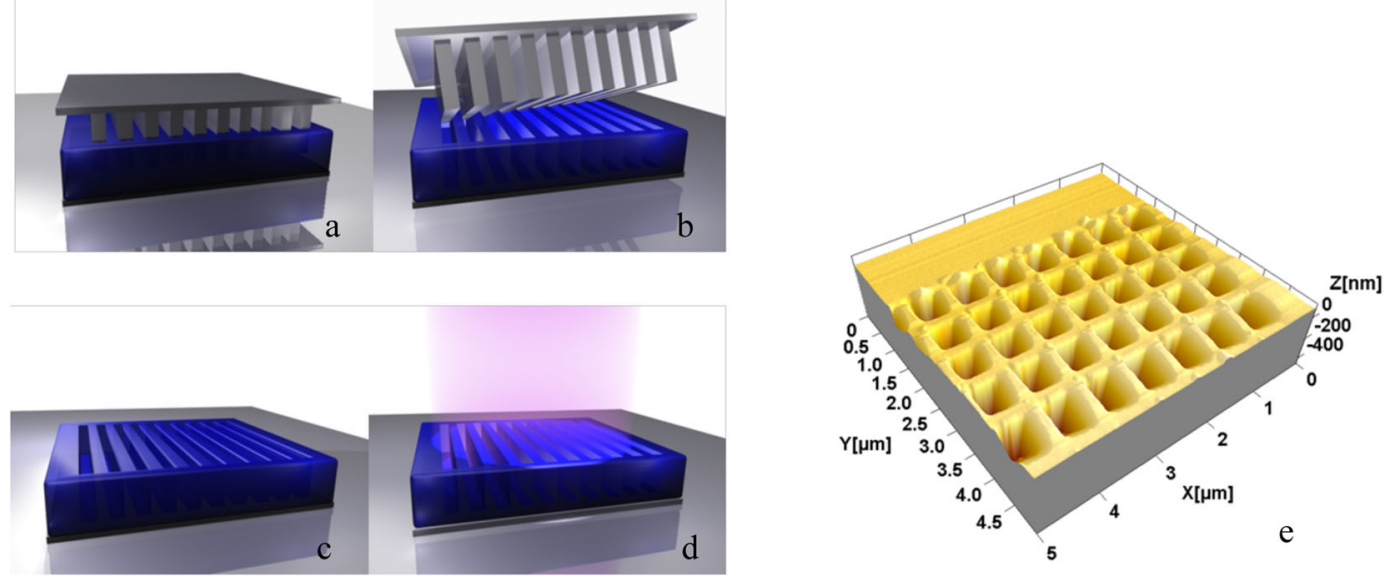

Fig. 2 Patterning process. (a) Pressing and (b) release of the stamp, (c) patterned micro- and nano-structures and (d) UV conversion of patterns into completely inorganic high refractive index features. e Example of patterned structures with $\mathrm{AR}=5$ : height $600 \mathrm{~nm}$ and width $120 \mathrm{~nm}$

\section{Results and discussion}

\subsection{Materials study and films behavior}

\subsubsection{Thermal behavior of in situ and ex situ films: rheology and FTIR analysis}

The in situ and ex situ films were prepared by two different synthesis strategies: the first uses a Ti-precursor, Titanium (IV) isopropoxide (TiOPr), and the second a presynthesized dense anatase nanoparticles in a titania sol. The specific compositions were selected after a preliminary set of NIL tests.

To control the overall process and achieve good quality patterns, we followed one of the most important parameters that influences the imprinting process: the viscosity of the resist and its variation with temperature. Both in situ and ex situ titania sols show a general increase of viscosity with temperature due to the crosslinking of precursors, with a slight decrease around $80{ }^{\circ} \mathrm{C}$ for the ex situ system just before a rapid increase at $\mathrm{T}>90^{\circ} \mathrm{C}$ (Fig. 3). It can be seen that the viscosities of the two sols are low with respect to the characteristic values of thermoplastic resists at typical imprinting temperatures. However, since the viscosity was evaluated on a thick sol film (around $500 \mu \mathrm{m}$ ), only the

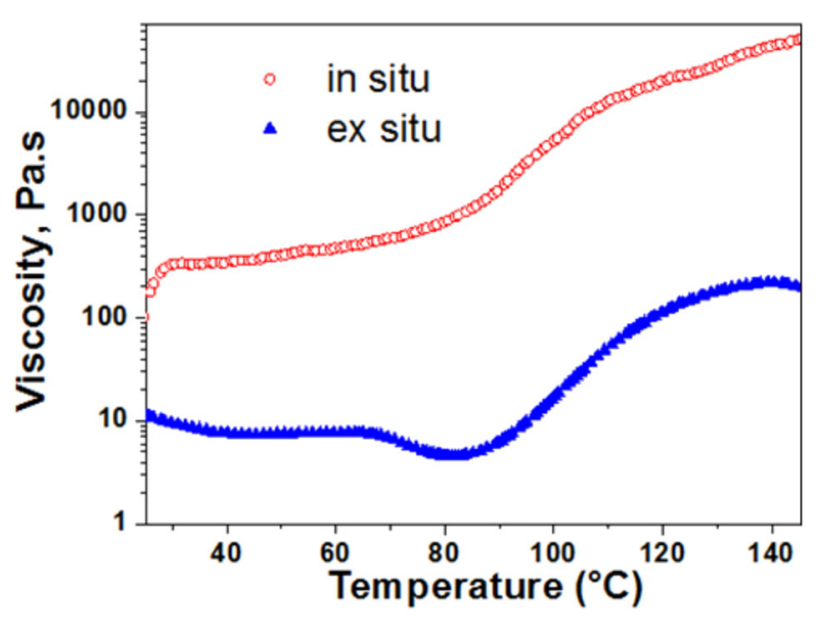

Fig. 3 Viscosity measurements of in situ and ex situ sols on films

viscosity trends and not the absolute values reported in Fig. 3 are significant.

The most striking feature of Fig. 3 was the slow but continuous increase of viscosity versus temperature of the in situ sol. This fact indicates that crosslinking reactions take place just after the film deposition at room temperature, continue at increasing temperature and accelerate their kinetics between 80 and $100{ }^{\circ} \mathrm{C}$. However, the 


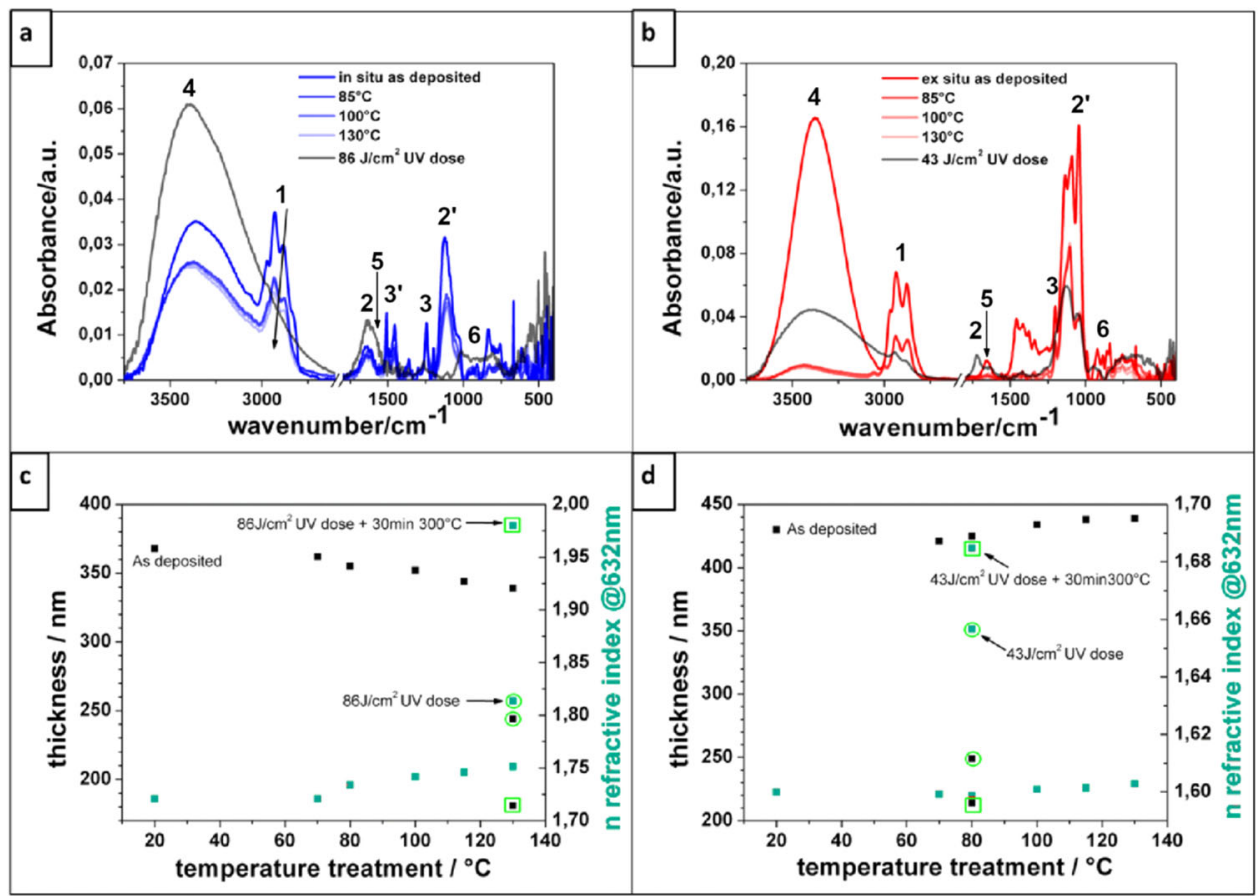

Fig. 4 FTIR spectra of in situ (a) and ex situ (b) films treated at different temperatures used during imprint experiments and after UV exposure. c, $\mathbf{d}$ Thickness and refractive index of films cured at different temperatures, UV cured after thermal treatment at the imprinting temperature and treated at $300^{\circ} \mathrm{C}$-after UV exposure and thermal treatment at the imprinting temperature. Data are collected from a

network formation was not completed even for $\mathrm{T}>$ $140^{\circ} \mathrm{C}$, because viscosity is still increasing at the end of the measurement. On the contrary, the ex situ film viscosity was constant until $70^{\circ} \mathrm{C}$, slightly decreasing at $80^{\circ} \mathrm{C}$, followed by a rapid growth and stabilization at $\mathrm{T}>$ $80-90{ }^{\circ} \mathrm{C}$. At these temperatures, crosslinking reactions become very effective, suggesting a complete hardening at around $140{ }^{\circ} \mathrm{C}$.

These diverse behaviors and the difference of one order of magnitude of viscosity values between the ex situ and in situ films, can be explained by analyzing the sol compositions: the in situ is a sol rich in pre polymerized TiOPr, that undergoes continuous crosslinking reactions with temperature; instead, the negligible amount of silicon and titanium alkoxides in the ex situ sol dissolved in a comparable amount of solvent prevents hardening of the network and requires higher temperatures in order to crosslink the alkoxides around anatase nanoparticles.

These observations were supported by FTIR spectra of films as-deposited and treated at increasing temperatures (Fig. 4a, b). The evaporation of the solvents (methoxyethanol, MEK and propanol) present in the films was the first feature clearly visible in both spectra: the doublets at 2930 and $2870 \mathrm{~cm}^{-1}\left(\nu_{\mathrm{as}}\left(\mathrm{CH}_{2}\right)\right.$ and $\nu_{\mathrm{s}}\left(\mathrm{CH}_{2}\right)$, respectively) and the peak at $1100 \mathrm{~cm}^{-1}$ due to $-\mathrm{C}-\mathrm{O}-\mathrm{C}-$ bond decreased minimum of 4 samples, giving a statistical maximum variation of about $10 \%$ for both thickness and refractive index measurement, due to the sample preparation reproducibility. Circled and squared off points refers to data of films exposed and then treated at $300^{\circ} \mathrm{C}$, respectively. The doses are indicated. Figures on the left and right refer to in situ and ex situ, respectively

with temperature. Moreover, the peak at $2830 \mathrm{~cm}^{-1}$ assigned to $-\mathrm{OCH}_{3}$ of methoxyethanol and the peaks at 1470 and 1370 due to methyl C-H asym./sym. bend of MEK disappeared in both the in situ and ex situ spectra after $85^{\circ} \mathrm{C}$-treatment. The reduction of alcoholic solvents content in the films upon thermal treatment was finally confirmed by the decreasing of $\mathrm{OH}$ absorption at $3400 \mathrm{~cm}^{-1}$, particularly evident for the ex situ after curing at $85^{\circ} \mathrm{C}$.

The abrupt decrease of the $-\mathrm{OH}$ band as well as all solvent absorbance peaks in the ex situ spectra at $85^{\circ} \mathrm{C}$ can be correlated to the sharp increase of viscosity around $90{ }^{\circ} \mathrm{C}$ visible in Fig. 3, confirming it was a consequence of the sol increasing in concentration and crosslinking. Likewise, the continuous viscosity increase during curing of the in situ system is accompanied by a gradual reduction of $-\mathrm{OH}$ and $-\mathrm{CH} 2\left(2930\right.$ and $\left.2870 \mathrm{~cm}^{-1}\right)$ absorbances. In this latter case, condensation occurred also through hydrolysis of residual alkoxy species (TiOPr and GPTMS), promoted by thermal curing, evident by the disappearance of the $2970 \mathrm{~cm}^{-1}$ and $2830 \mathrm{~cm}^{-1}$ absorbances. The former was due to the $\mathrm{C}-\mathrm{H}$ bond of isopropoxide species in the titanium alkoxide precursor and the latter to unreacted $\mathrm{Si}-\mathrm{OCH}_{3}$ groups.

This viscosity analysis allowed the material's structural evolution to be controlled during NIL and the correct 
temperature to be chosen to avoid incomplete filling of the stamp, caused by premature or insufficient crosslinking of the film or the absence of solvents helping material flow during imprinting. Then, the time and pressure schedule were optimized for a good quality depth pattern and, in particular, to obtain a complete crosslink of the resist once the cavities were filled and to maintain the patterned shape after pressure removal.

Therefore, optimized schedules were selected to be: $20 \mathrm{~min}$ at $100-130{ }^{\circ} \mathrm{C}$ with a pressure of $30 \mathrm{MPa}$ for the in situ system and temperatures ranging between room temperature to $80^{\circ} \mathrm{C}$ for the ex situ system.

\subsubsection{UV curing of in situ and ex situ}

Resists are generally photo-cured to initiate polymerization reactions of organic monomers or degradation of UV absorbing species often coordinated to the inorganic network by chelating agents $[40,41]$. The peculiarity of these $\mathrm{TiO}_{2}$ based resists is the possibility to convert patterned structures into inorganic oxide by photo-curing, determined from the photoactivity of $\mathrm{TiO}_{2}$ network that locally induce the degradation of organic species present in the material under UV illumination.

As can be seen by FTIR spectroscopy (Fig. 4a, b, black lines), after UV exposure the two sharp bands at 2930 and $2870 \mathrm{~cm}^{-1}$, arising from the presence of residual organic component, progressively decreased and almost disappeared. The degradation of organic species was confirmed by the appearance of a peak at $1725 \mathrm{~cm}^{-1}$ and by the reduction of the absorbance at $1100 \mathrm{~cm}^{-1}$. The former peak is related to the absorption region of $\mathrm{C}=\mathrm{O}$ bonds that can arise from the degradation of more labile organic species, such as the $\mathrm{CH}_{2}-\mathrm{O}-\mathrm{CH}_{2}$ bond of the etheric group in the propylic chain of GPTMS or surfactants/dispersants used in the ex situ commercial dispersion [42]. The latter absorption was due to the degradation of the $\mathrm{C}-\mathrm{O}$ bond of the ether group. The peaks at 1244 and $1200 \mathrm{~cm}^{-1}$, related to the antisymmetric ring stretching of the epoxides and to the symmetric stretching vibration of $\mathrm{CH}^{2}$ groups in the propylic chain, respectively, and the aromatic ring vibration modes at $1613-1585$ and $1510-1470 \mathrm{~cm}^{-1}$ in the in situ spectrum (para-substituted phenyl groups stretching vibrations) decreased with UV exposure dose, indicating that ring opening and degradation of the organic chains occurred. Simultaneously, the growth of the band at $3400-3200 \mathrm{~cm}^{-1}$ deriving from formation of $\mathrm{H}_{2} \mathrm{O}$ and $-\mathrm{OH}$ species and the appearance of the $1640 \mathrm{~cm}^{-1}$ peak due to absorption of water molecules through an $\mathrm{H}$ bond with $\mathrm{C}=\mathrm{O}$ groups, that are known to be very hydrophilic, were observed in both spectra. Finally, the slight increase of the $950 \mathrm{~cm}^{-1}$ band absorbance with UV exposure can be ascribed to both condensation of the Ti-O-Si network and to $\mathrm{Si}-\mathrm{OH}$ stretching vibrations [43-46]. Both absorbances may be present at this low treatment temperature.

All in all, these observations indicated that the UV photo-curing in the presence of the photocatalytic $\mathrm{TiO}_{2}$ network can initiate a marked densification, which is not achievable with a mild thermal curing, as is confirmed by the refractive index and thickness changes with UV dose reported in the following.

\subsubsection{Refractive index change with temperature and UV curing}

The refractive index and thickness of un-patterned films are reported in Fig. 4c, d. Only in situ films thickness showed an almost linear decrease accompanied by a slight refractive index growth, while the ex situ refractive index and thickness remained constant with thermal treatment. A comparison between in situ and ex situ thickness change showed that the shrinkage of in situ films after treatment at $130^{\circ} \mathrm{C}$ is lower than $8 \%$, while the ex situ film did not contract. At this temperature, the organic component (apart from the solvent) was still present in both films, but the densification of in situ sample was more efficient, as confirmed by the refractive index of films treated at $130^{\circ} \mathrm{C}: 1.75$ and 1.60 for in situ and ex situ, respectively. Moreover, even if in the ex situ film, the presence of anatase nanoparticles should further contribute to increasing the film's refractive index, a poor compaction efficiency of the nanoparticles clearly took place with a consequent high final porosity of the film.

A $28 \%$ and $40 \%$ shrinkage, for in situ and ex situ films, respectively, was observed after UV exposure of films cured at the selected imprinting temperatures $\left(130^{\circ} \mathrm{C}\right.$ for in situ and $80^{\circ} \mathrm{C}$ for ex situ), accompanied by a refractive index rise up to 1.82 and 1.66 at $632 \mathrm{~nm}$, respectively. Eventually, a refractive index up to 2 at $632 \mathrm{~nm}$ was reached with a thermal treatment at $300{ }^{\circ} \mathrm{C}$ for the in situ film.

However, these refractive index values compared with those of both amorphous and crystalline dense $\mathrm{TiO}_{2}(n$ around 2.4-2.6 [47]), suggested that the films were still quite porous, even taking into consideration the presence of the silica phase present in both in situ and ex situ films. The porosity of in situ films increased due to the removal of volatile organic species degraded under UV and from the presence of uncondensed $\mathrm{TiOH}$ bonds, while in the ex situ film it was the result of spaces between dense anatase nanoparticles that did not sinter at these low temperatures.

\subsubsection{Crystalline structures of ex situ and in situ films}

The crystallinity of the ex situ and in situ films, both asdeposited and UV exposed, was measured by XRD (Fig. 5). As expected, the (101) peak of the anatase phase at $2 \theta=25.3^{\circ}$ 


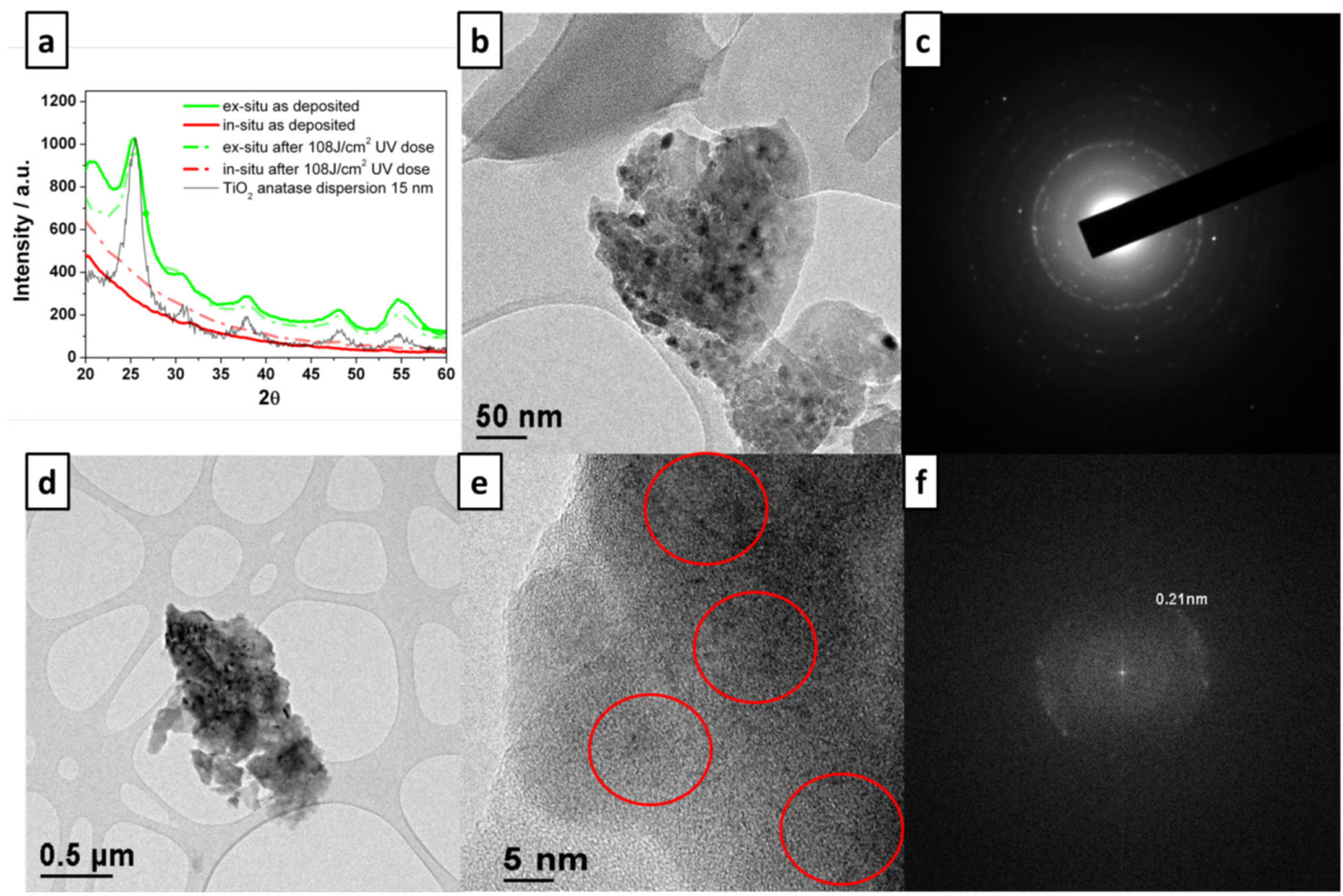

Fig. 5 XRD patterns of ex situ and in situ films as-deposited and after UV exposure (a). TEM images of an in situ particle of anatase after $44 \mathrm{~J} / \mathrm{cm}^{2}$ $\mathrm{UV}$ exposure dose $(\mathbf{b}, \mathbf{d}, \mathbf{e})$ together with the diffraction images $(\mathbf{c}, \mathbf{f})$

before and after UV irradiation was present in ex situ films (the patterns are compared with that of anatase particles dispersion used in the synthesis). On the contrary, no diffraction peaks were observed for the as'deposited in situ film and for the same film after $108 \mathrm{~J} / \mathrm{cm}^{2} \mathrm{UV}$ dose exposure, indicating their amorphous structure.

It is well-known that the anatase titania phase shows the highest photoactivity compared to brookite or rutile phases, while amorphous titania generally exhibits negligible photocatalytic activity. It is in fact commonly accepted that amorphous metal oxides contain high concentrations of defects that will invariably function as rapid electron-hole recombination centers to render them inactive [48-50]. However, although in situ films were supposed to be totally amorphous, they probably displayed a relevant photocatalytic effect: a possible explanation is given by TEM analysis that revealed the presence of small quantities of a crystalline phase made of small crystals undetectable by XRD.

TEM analysis of the in situ films after $44 \mathrm{~J} / \mathrm{cm}^{2}$ UV exposure dose is reported in Fig. $5 \mathrm{~b}$; the occasional presence of crystalline phases dispersed in an amorphous background was detected and identified from diffraction analysis as anatase and rutile.

\subsection{NIL of in situ and ex situ films}

Due to their slow hardening, in situ films could be imprinted, down to sub-100 nm (Fig. 6b) at a range of temperatures from RT to the highest tested $\left(130^{\circ} \mathrm{C}\right)$, preserving sufficiently soft texture. NIL of in situ films confirmed the expectations from FTIR analysis, refractive index and rheological measurements. The network hardening and a complete filling of the cavities was reached in $20 \mathrm{~min}$ at $100-130{ }^{\circ} \mathrm{C}$ with a pressure of $30 \mathrm{MPa}$ as confirmed by the crack-free flat profile of the structures, particularly evident in Fig. 6a.

In the case of the stamp with $>0.5$ um deep cavities, the difference between stamp depth and the resulting AFM profile of the structures was $30 \%$ (Fig. 7): in fact, with a $730 \mathrm{~nm}$ stamp depth, lines $510 \mathrm{~nm}$ high were obtained. Since the shrinkage of in situ flat films after treatment at $100{ }^{\circ} \mathrm{C}$ was lower than $5 \%$ (Fig. 3), a possible contribution of an incomplete filling of the structures has to be considered.

In the ex situ system, as expected from rheological measurements and FTIR spectra, the best imprint results, in terms of structure sharpness and uniformity of filling, were achieved with temperatures ranging between room 
Fig. 6 SEM micrographs of $\mathrm{TiO}_{2}$ in situ patterns obtained with stamp depths of $360 \mathrm{~nm}$ (a) and $160 \mathrm{~nm}(\mathbf{b})$ at $100{ }^{\circ} \mathrm{C}$; ex situ patterns obtained with a stamp depth of $730 \mathrm{~nm}$ (c) and $160 \mathrm{~nm}(\mathbf{d})$ at room temperature

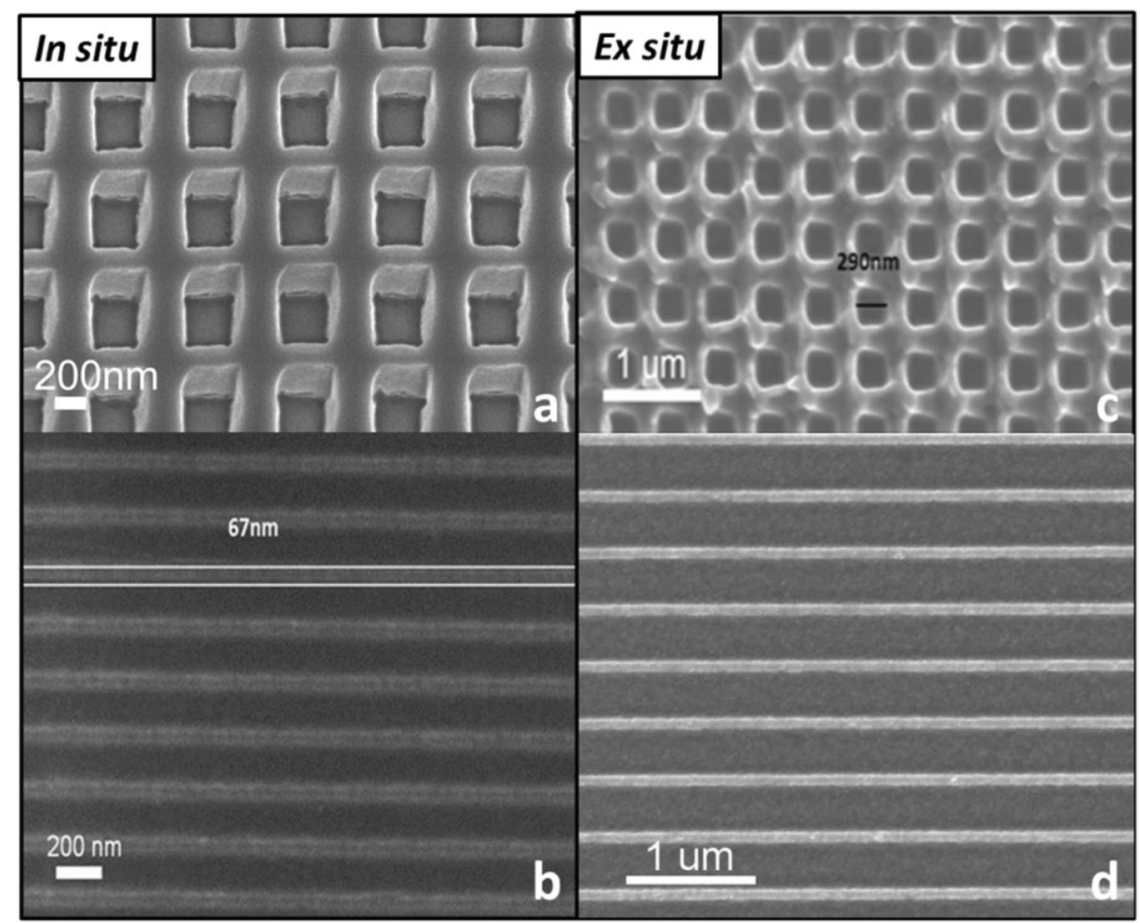

temperature to $80^{\circ} \mathrm{C}$ and down to $100 \mathrm{~nm}$ lines (Fig. 6d). The possibility of obtaining imprinting at low temperatures was due to the low content of alkoxides in the ex situ system. The filling of the cavities was mainly achievable due to the presence of the solvent in the films up to $80^{\circ} \mathrm{C}$ : the rheological curve showed, in fact, an abrupt increase in viscosity at temperature above $80-100{ }^{\circ} \mathrm{C}$, mainly due to solvent evaporation with a minor contribution from alkoxide crosslinking. Structures with depth of up to $630 \mathrm{~nm}$ were produced with stamp cavity depths of $730 \mathrm{~nm}$ as can be seen from the corresponding AFM profile in Fig. 7: the measured difference between stamp depth and AFM profile of the structures is $15 \%$, probably due to incomplete filling of cavities rather than shrinkage (which is negligible in flat ex situ films as already shown in Fig. 4).

Figure $8 \mathrm{~b}$ shows an example of the application of these nanopatterned films as antireflecting coating. In the figure is shown an AFM image of a $\mathrm{TiO}_{2}$ in situ hexagonal array of dense nanostructures achieved by imprinting a flat film, deposited on glass, with a $\mathrm{Ni}$ master. In Fig. 8c also the transparency of the films can be appreciated, as the flat films has a transmittance between 85 and 90\%. The antireflective effect is also evident from the figure, as the transmittance increases after patterning, confirming the fidelity of master replication

\subsection{UV curing of in situ and ex situ patterns}

After imprinting, patterned surfaces were UV exposed, with the minimum dose needed to eliminate organic component and transform the film in a totally inorganic material. The exposure was expected to lead to a further vertical and eventually lateral shrinkage, based on the data of Fig. 3. However, the shrinkage exhibited by in situ films was very low, as demonstrated by the AFM images of Fig. 7 after UV exposure. The lateral profile of simple gratings (period $1.5 \mu \mathrm{m}$ and stamp depth $730 \mathrm{~nm}$ ) revealed that the mean height of the gratings changed from $510 \mathrm{~nm}$ after imprinting to $479 \mathrm{~nm}$ with a resulting vertical shrinkage around $7 \%$, much lower than a value of $28 \%$ measured on flat films treated at $130{ }^{\circ} \mathrm{C}$ and then exposed to the same dose, as shown in Fig. 3.

This effect is also more evident in ex situ films, that did not undergo vertical shrinkage after irradiation, as shown by the grating of Fig. 7 after UV exposure, with respect to a measured shrinkage of $40 \%$ shown in Fig. 3 after curing at $80{ }^{\circ} \mathrm{C}$ and UV exposure at the same dose.

Moreover, it is noteworthy that both in situ and ex situ patterns showed a relatively low vertical shrinkage, not accompanied by a lateral shrinkage that can be explained by the constraint deriving from the adhesion to the substrate. Therefore, in the imprinted structures, all the deformation necessary to compensate for the degradation of the organic part of the film was probably "absorbed" by vertical shrinkage. This behavior represents an important advantage simplifying the prediction of the final geometry of the structures: only vertical shrinkage must be considered during the design of the initial thickness. This behavior can be due to simultaneous application of pressure and temperature during the imprinting process, in which the thermal step is 

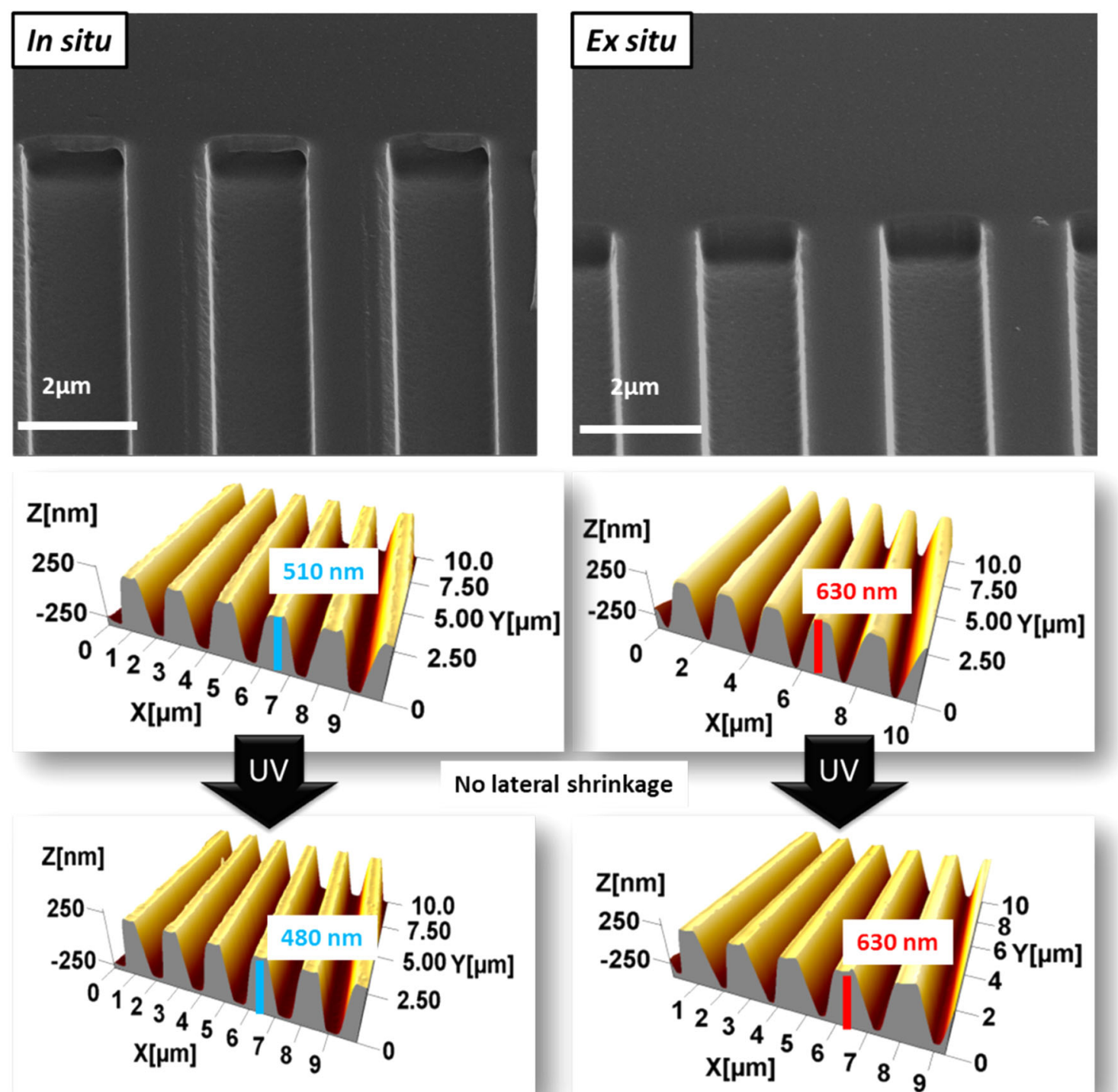

Fig. $7 \mathrm{SEM}$ and AFM images of (left) $\mathrm{TiO}_{2}$ in situ imprinted with a $730 \mathrm{~nm}$ depth stamp at $100^{\circ} \mathrm{C}$ before and after exposure to $86 \mathrm{~J} / \mathrm{cm}^{2} \mathrm{UV}$ dose; and (right) $\mathrm{TiO}_{2}$ ex situ imprinted with a $730 \mathrm{~nm}$ depth stamp at room temperature and then exposed to $43 \mathrm{~J} / \mathrm{cm}^{2} \mathrm{UV}$ dose

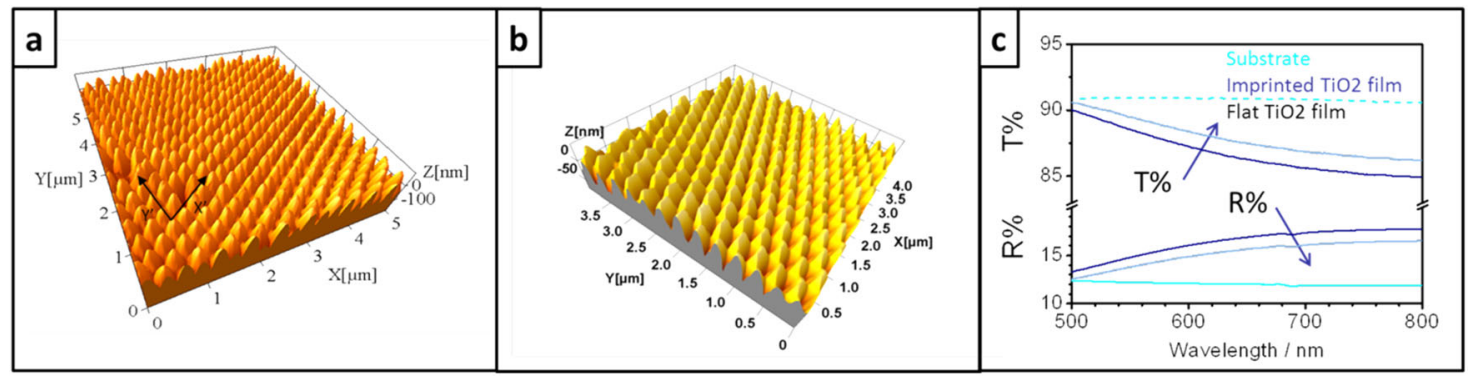

Fig. 8 AFM images of $\mathrm{TiO}_{2}$ in situ hexagonal array of dense nanostructures (b), imprinted with a Ni master (a), and antireflective effect of a patterned film deposited on glass (c). Master features: depth $140 \mathrm{~nm}$, period $300 \mathrm{~nm}$ 
evidently more effective towards the compaction of the film than pure thermal treatment at the same temperature, thanks to the applied pressure. As a consequence, we observe that the main effect of post UV treatment is promote the organic degradation rather than further shrinkage. Importantly, the lack of shrinkage would also help to maintain the shape and quality of the pattern after UV exposure as no cracks were observed at the end of the process.

\section{Conclusions}

Direct printing of spin-on high refractive index transparent materials was demonstrated. Unusual depth up to $600 \mathrm{~nm}$ and aspect ratio larger than 5 were obtained by combining thermal NIL with UV curing and hybrid organic-inorganic spin-on films.

Two distinct bottom-up synthetic approaches, called in situ and ex situ were prepared. In the in situ approach, the $\mathrm{TiO}_{2}$ is formed simultaneously with the synthesis of the HOI material, while in the ex situ one $\mathrm{TiO}_{2} \mathrm{NPs}$ are added to the material already synthesized. The two systems were optimized in order to obtain, after patterning by thermal imprint, in the first case amorphous and in the second case crystalline titania crack-free micro- and nanofeatures with smallest sizes of $70 \mathrm{~nm}$ width and up to $630 \mathrm{~nm}$ deep. The further UV irradiation converted imprinted films to totally inorganic patterns, without lateral shrinkage, loss of integrity or aspect ratio. Refractive indexes up to 1.82 at $632 \mathrm{~nm}$ and up to 2 at $632 \mathrm{~nm}$ were measured, without and with an eventual thermal treatment at $300{ }^{\circ} \mathrm{C}$, respectively.

\section{Experimental section}

\subsection{Materials and synthesis}

Titanium(IV) isopropoxide (TiOPr, purum, $\geq 97.0 \%$ ), 3-glycidoxypropyltrimethoxysilane GPTMS and Bis[4(glycidyloxy)phenyl]methane BFGDE were all purchased from Aldrich and used as received (Fig. 2). The dispersion of $\mathrm{TiO}_{2}$-anatase $15 \mathrm{~nm}$ particles in 2- propanol $(20 \mathrm{wt} \%)$ was purchased from MKnano.

The two methods used in our experiments to fabricate photosensitive hybrid organic-inorganic (HOI) sol-gel based spin-on $\mathrm{TiO}_{2}$ resists are named in situ and ex situ synthesis (Fig. 1).

\subsubsection{In situ synthesis}

the titania network is formed simultaneously with the synthesis of the HOI material, by hydrolysis and condensation of TiOPr (90 mol\%) and minor amounts (10 mol\%) of silica precursor (GPTMS). GPTMS (molar ratio H2O:GPTMS $=3: 1$ ) was first hydrolyzed in basic conditions for $1 \mathrm{~h}$ at $\mathrm{RT}$ and $2 \mathrm{~h}$ at $80^{\circ} \mathrm{C}$ under stirring in ambient air. 2-methoxyethanol, MetOEtOh, and $\mathrm{NaOH}$ ( $0.3 \mathrm{~mol} \%$ in GPTMS) were then added to the GPTMS solution in this order. Separately, TiOPr was added to MetOEtOH at a 1:1 volume ratio, and the solution was stirred for about $10 \mathrm{~min}$. The two prepared solutions were then mixed and the monomer bisphenol $\mathrm{F}$ diglycidyl ether (BFDGE) (5\% molar with respect to $\mathrm{TiO}_{2}$ content) was added to the solution to increase the processability and the final film thickness. The synthesis was carried out in MetOEtOh to obtain a final sol concentration of $100 \mathrm{~g} / \mathrm{l}$ $\mathrm{TiO}_{2}$ content.

\subsubsection{Ex situ synthesis}

TiOPr was added to a dispersion of $\mathrm{TiO}_{2}$-anatase $(15 \mathrm{~nm}$ particles mean size) in 2-Propanol (20wt\%); this solution was loaded with $30 \mathrm{wt} \%$ of a previously prepared silica sol based on GPTMS, called GB, ${ }^{1}$ which improves film quality, increases layer thickness (up to $1.5 \mu \mathrm{m}$ thickness, depending on the spin-coating speed) and makes possible film deformation during NIL. GB sol is obtained by GPTMS hydrolysis in basic conditions for $1 \mathrm{~h}$ at $80^{\circ} \mathrm{C}$ (GPTMS: $\mathrm{H}_{2} \mathrm{O}: \mathrm{NaOH}=1: 3: 0.003$, sol in MetOEtOh $150 \mathrm{~g}^{-1} \mathrm{SiO}_{2}$ ). The final amount of titanium isopropoxide is $10 \mathrm{~mol} \%$ with respect to GPTMS.

The sol was left stirring for $20 \mathrm{~min}$ at RT followed by $10 \mathrm{~min}$ at $70^{\circ} \mathrm{C}$. The solvent (MEK) was added to obtain the final sol concentration of $90 \mathrm{~g} / \mathrm{l}\left(\mathrm{TiO}_{2}\right)$, and a $\mathrm{SiO}_{2}: \mathrm{TiO}_{2}$ molar ratio of 1:3.

The sols were filtered using a microporous membrane ( $0.2 \mu \mathrm{m}$ Millipore) to remove large particles and improve the resist spin-coating quality and deposited by spincoating technique at different speeds to obtain films with the desired thickness.

Glass or silicon substrates were used for the following characterization or processes. The substrate was cleaned using plasma procedures in order to remove contaminants which may lead to poor adhesion or defects formation in the resist layer. Films were deposited by spin-coating the fresh sols immediately after preparation. By using different speeds, variable thickness was obtained, up to $1.5 \mu \mathrm{m}$ for the ex situ film.

\subsubsection{Characterization}

the compositions of the films deposited on silicon wafers were examined by a Fourier transform infrared spectrometer (Jasco FT-IR-620) in the range of $400-4500 \mathrm{~cm}^{-1}$ with a resolution of $4 \mathrm{~cm}^{-1}$, on the basis of literature data [43-46]. In Fig. $4 \mathrm{a}, \mathbf{b}$ 
peaks are labeled as follow: 1- two sharp bands at 2930 and $2870 \mathrm{~cm}^{-1}, \mathbf{2}$ - peak at $1725 \mathrm{~cm}^{-1}, \mathbf{2}$ '- peak at $1100 \mathrm{~cm}^{-1}, \mathbf{3}$ peaks at 1244 and $1200 \mathrm{~cm}^{-1}, \mathbf{3}^{\prime}$ - set of bands of aromatic ring vibrations at $1613-1585$ and $1510-1470 \mathrm{~cm}^{-1}$ for the in situ film, 4- band at $3400-3200 \mathrm{~cm}^{-1}, 5$ - peak at $1640 \mathrm{~cm}^{-1}$ (partially overlapped with peak at $1725 \mathrm{~cm}^{-1}$ ), 6- $950 \mathrm{~cm}^{-1}$ absorbance band.

The UV-Vis absorption of the films, deposited on glass substrates, was characterized using a UV-Vis spectrophotometer (JASCO V-570) in the wavelength range $200-600 \mathrm{~nm}$.

The film thickness was examined using a profilometer and the quality of the gratings was characterized by Atomic Force Microscopy (NT-MDT) and SEM (LEO 1550).

The effects of thermal treatment and UV exposure on the refractive index and thickness of the hybrid titania sol-gel films were recorded by ellipsometric measurements (VVase J.A. Woollam Ellipsometer).

The film structure and titania crystalline cluster size were investigated through TEM (Jeol 3010 apparatus operated at $300 \mathrm{kV}$ with a high-resolution pole) and X-ray diffraction (XRD) using an X-ray diffractometer (Philips PW 1729) with $\mathrm{Cu} \mathrm{K \alpha}$ irradiation.

\subsubsection{Imprint lithography conditions}

the synthesized HOI titania films up to $1.5 \mu \mathrm{m}$ were spin coated on silicon substrates and imprinted at temperatures ranging from room temperature (RT) to $130{ }^{\circ} \mathrm{C}$ with pressures between 20 and $40 \mathrm{MPa}$. Stamp materials, silicon (purchased from Silicon materials) or ORMOSTAMP (Micro resist technology), possessing multi micro- to nano- metric feature patterns and feature depths from 150 to $730 \mathrm{~nm}$, and $\mathrm{Ni}$ stamp (NIL-...) with antireflecting features (depth $140 \mathrm{~nm}$, period $300 \mathrm{~nm}$ ) were used. The anti-adhesion layer was obtained using stamp silanization with $1 \mathrm{H}, 1 \mathrm{H}, 2 \mathrm{H}, 2 \mathrm{H}-$ Perfluorooctyl-trichlorosilane $\quad 97 \%$ (Aldrich) in the vapor phase under vacuum for $3 \mathrm{~h}$.

After thermal imprinting (T-NIL) the patterns were UV exposed at doses of 86 or $43 \mathrm{~J} / \mathrm{cm}^{2}$ (for in situ and ex situ respectively) selected to obtain totally inorganic features and eventually treated at temperatures of up to $300^{\circ} \mathrm{C}$ for $30 \mathrm{~min}$ to further increase the refractive index.

Acknowledgements We thank prof. Juergen Brugger - EPFL - for his scientific support and discussions and Dr. Agnese Virginia Savegnago for technical support.

Funding Open access funding provided by UniversitÃ degli Studi di Padova within the CRUI-CARE Agreement.

\section{Compliance with ethical standards}

Conflict of Interest The authors declare no competing interests.
Publisher's note Springer Nature remains neutral with regard to jurisdictional claims in published maps and institutional affiliations.

Open Access This article is licensed under a Creative Commons Attribution 4.0 International License, which permits use, sharing, adaptation, distribution and reproduction in any medium or format, as long as you give appropriate credit to the original author(s) and the source, provide a link to the Creative Commons license, and indicate if changes were made. The images or other third party material in this article are included in the article's Creative Commons license, unless indicated otherwise in a credit line to the material. If material is not included in the article's Creative Commons license and your intended use is not permitted by statutory regulation or exceeds the permitted use, you will need to obtain permission directly from the copyright holder. To view a copy of this license, visit http://creativecommons. org/licenses/by/4.0/.

\section{References}

1. Lu C, Yang B (2009) High refractive index organic-inorganic nanocomposites: design, synthesis and application. J Mater Chem 19:2884-2901

2. Ito $\mathrm{S}$, Murakami TN, Comte $\mathrm{P}$, Liska P, Grätzel C, Nazeeruddin MK, Grätzel M (2008) Fabrication of thin film dye sensitized solar cells with solar to electric power conversion efficiency over $10 \%$. Thin Solid Films 516:4613-4619

3. Antonello A, Jia B, He Z, Buso D, Perotto G, Brigo L, Brusatin G, Guglielmi M, Gu M, Martucci A (2012) Optimized electroless silver coating for optical and plasmonic applications Plasmonics 2012. https://doi.org/10.1007/s11468-012-9352-6

4. Que W, Zhou Y, Lam YL, Chan YC, Kam CH (2001) Preparation and characterizations of $\mathrm{SiO}_{2} / \mathrm{TiO}_{2} / \gamma$-glycidoxypropyltrimethoxysilane compositematerials for optical waveguides. Appl. Phys. A 73:171-176. https://doi.org/10.1007/s003390000612

5. Langlet et al. (2001) Low temperature preparation of high refractive index and mechanically resistant sol-gel $\mathrm{TiO}_{2}$ films for multilayer antireflective coating applications. J Sol-Gel Sci Technol 22:139-150

6. Macwan DP, Dave PN, Chaturvedi S (2011) A review on nano$\mathrm{TiO}_{2}$ sol-gel type syntheses and its applications. J Mater Sci 46:3669-3686

7. Le Guevel X, Palazzesi C, Prosposito P, Della G (2008) Giustina and Giovanna Brusatin Influence of chelating agents on the photopolymerization of hybrid Ti-based waveguides. J Mater Chem 18:3556-3562

8. Brigo L, Michieli N, Artiglia L, Scian C, Rizzi GA, Granozzi G, Mattei G, Martucci A, Brusatin G (2014) Silver nanoprism arrays coupled to functional hybrid films for localized surface plasmon resonance-based detection of aromatic hydrocarbons. ACS Appl Mater Interfaces 6(10):7773-7781

9. Antonello A, Brusatin G, Guglielmi M, Bello V, Mattei G, Zacco G, Martucci A (2011) Nanocomposites of titania and hybrid matrix with high refractive index. J Nanopart Res 13:1697-1708

10. Ozawa N, Yabe H, Yao T (2003) Formation of titania submicrometer patterns by the combination of synthesis from an aqueous solution and transcription of a resist pattern. J Am Ceram Soc 86(11):1976-1978

11. Francioso L, Taurino AM, Forleo A, Siciliano P (2008) $\mathrm{TiO}_{2}$ nanowires array fabrication and gas sensing properties. Sens Actuators B Chem 130:70-76

12. Xia D, Jiang Y-B, He X, Brueck SRJ (2010) Titania nanostructure arrays from lithographically defined templates. Appl Phys Lett 97:223106 
13. Yang P, Yang M, Zou S, Xie J, Yang W (2007) Positive and negative $\mathrm{TiO}_{2}$ micropatterns on organic polymer substrates. J Am Chem Soc 129:1541-1552

14. Masuda Y, Sugiyama T, Lin H, Seo WS, Koumoto K (2001) Selective deposition and micropatterning of titanium dioxide thin film on self-assembled monolayers. Thin Solid Films 382:153-157

15. Brigo L, Gazzola E, Cittadini M, Zilio P, Zacco G, Romanato F, Martucci A, Guglielmi M, Brusatin G (2013) Short and long range surface plasmon polariton waveguides for xylene sensing. Nanotechnology 24:155502. (10pp)

16. Wathuthanthri I, Liu Y, Du K, Xu W, Choi C-H (2013) Simple holographic patterning for high-aspect-ratio three-dimensional nanostructures with large coverage area. Adv Funct Mater 23:608-618

17. Sander MS, Côté MJ, Gu W, Kile BM, Tripp CP (2004) Template-assisted fabrication of dense, aligned arrays of titania nanotubes with well-controlled dimensions on substrates. Adv Mater 16:2052-2057

18. Saifullah MSM, Subramanian KRV, Tapley E, Kang DJ, Welland ME, Butler M (2003) Sub-10 nm electron beam nanolithography using spin-coatable $\mathrm{TiO}_{2}$ resists. Nano Lett 3:1587-1591

19. Liu B, Ho ST(2008) Sub-100 nm nanolithography and pattern transfer on compound semiconductor using sol-gel-derived $\mathrm{TiO} 2$ resist J Electrochem Soc 155:P57-P60

20. Garipcan B, Winters J, Atchison JS, Cathell MD, Schiffman JD, Leaffer OD, Nonnenmann SS, Schauer CL, Pis, kin E, Nabet B, Spanier JE (2008) Controllable formation of nanoscale patterns on $\mathrm{TiO}_{2}$ by conductive-AFM nanolithography. Langmuir 24:8944-8949

21. Passinger S, Saifullah MSM, Reinhardt C, Subramanian KRV, Chichkov BN, Mark E (2007) Welland, direct 3D patterning of $\mathrm{TiO}_{2}$ using femtosecond laser pulses. Adv Mater 19:1218-1221

22. Voicu NE, Saifullah MSM, Subramanian KRV, Welland ME, Steiner U (2007) $\mathrm{TiO}_{2}$ patterning using electro-hydrodynamic lithography. Soft Matter 3:554-557

23. Dal Zilio S, Della Giustina G, Brusatin G, Tormen M (2010) Microlenses arrays on large area UV transparent hybrid sol-gel materials for optical tools. Microelectron Eng 87:1143-1146

24. Guo J (2007) Nanoimprint lithography: methods and material requirements. Adv Mater 19(4):495-513

25. Chou Y, Krauss P, Renstrom P (1996) Imprint lithography with 25-nanometer resolution. Science 272(5258):85-87

26. Bhushan B (2007) Nanoimprint lithography, chapter 8. In Springer handbook of nanotechnology. Springer, Berlin, Heidelberg. https://doi.org/10.1007/978-3-540-29857-1_8

27. Park HH, Choi D-G, Zhang X, Jeon S, Park S-J, Lee S-W, Kim S, Kim K-D, Choi J-H, Lee J, Yun DK, Lee KJ, Park A-H, Hill RH, Jeong J-H (2010) Photo-induced hybrid nanopatterning of titanium dioxide via direct imprint lithography. J Mater Chem 20:1921-1926

28. Park H-H, Zhang Xin, Lee S-W, Jeong D-J, Lee S-M, Kim K-D, Choi D-G, Choi J-H, Lee J, Lee E-S, Kang HK, Park H-Ho, Hill $\mathrm{RH}$, Jeong J-H (2011) Optical characterization of anatase $\mathrm{TiO}_{2}$ films patterned by direct ultraviolet-assisted nanoimprint lithography. Microelectron Eng 88:923-928

29. Wu C-C, Hsu SL-C (2010) Preparation of epoxy/silica and epoxy/ titania hybrid resists via a sol-gel process for nanoimprint lithography. J Phys Chem C 114:2179-2183

30. Lee BK, Hong L-Y, Lee HY, Kim D-P, Kawai T (2009) Replica mold for nanoimprint lithography from a novel hybrid resin. Langmuir 25(19):11768-11776

31. Li M, Tan H, Chen L, Wang J, Chou SY(2003) Large area direct nanoimprinting of $\mathrm{SiO} 2-\mathrm{TiO} 2$ gel gratings for optical applications J Vac Sci Technol B 21:260
32. Lim SH, Saifullah MSM, Hussain H, Loh WW, Low HY (2010) Direct imprinting of high resolution $\mathrm{TiO}_{2}$ nanostructures. Nanotechnology 21:285303

33. Ganesan R, Dumond J, Saifullah MSM, Lim SH, Hussain H, Low HY (2012) Direct patterning of $\mathrm{TiO}_{2}$ using step-and-flash imprint lithography. ACS Nano 6(2):1494-1502

34. Parashar VK, Styah A, Cuche E, Depeursinge C, Gijs MAM (2003) Diffractive optical elements in titanium oxide for moems applications. In TRANSDUCERS '03 The 12th International Conference on Solid State Senson, Actuators and Mbmsystems, Boston

35. Göbel OF, Nedelcu M, Steiner U (2007) Soft lithography of ceramic patterns. Adv Funct Mater 17:1131-1136

36. Yoon K-m, Yang K-y, Lee H (2009) Fabrication of polycrystalline $\mathrm{TiO}_{2}$ nanopatterns by $\mathrm{TiO}_{2}$ sol base imprint lithography. Thin Solid Films 518:126-129

37. Brusatin G, Della Giustina G, Romanato F, Guglielmi G (2008) Design of hybrid sol-gel films for direct $\mathrm{x}$-ray and electron beam nanopatterning. Nanotechnology 19:175306

38. Williams SS, Hampton MJ, Gowrishankar V, Ding I-K, Templeton JL, Samulski ET, DeSimone JM, Michael D (2008) McGehee nanostructured titania-polymer photovoltaic devices made using PFPE-based nanomolding techniques. Chem Mater 20 (16):5229-5234

39. Kim W-S, Yoon KB, Bae B-S (2005) Nanopatterning of photonic crystals with a photocurable silica-titania organic-inorganic hybrid material by a UV-based nanoimprint technique. J Mater Chem 15:4535-4539. 4535

40. Segawa H, Adachi S, Arai Y, Yoshida K (2003) Fine patterning of hybrid titania films by ultraviolet irradiation. J Am Ceram Soc 86 (5):761-764

41. Imao T, Hazama D, Noma N, Ito S (2006) Photopatterning of titanium oxide gel films prepared from titanium alkoxide modified with hydroxyl-substituted aromatic setone. J Ceram Soc Jpn 114 (3):238-240

42. Brusatin G, Della Giustina G, Guglielmi M, Innocenzi P (2006) Photocurable glycidoxypropyltrimethoxysilane based sol-gel hybrid materials. Prog Solid State Chem 34:223-229

43. Fidalgo A, Ilharco LM (2001) The defect structure of sol-gelderived silica/polytetrahydrofuran hybrid films by FTIR J NonCryst Solids 283:144-154

44. Gao X, Wachs IE (1999) Titania-Silica as Catalysts: Molecular Structural Characteristics and Physico-Chemical Properties Catal Today 51:233-254

45. Que W, Hu X (2003) Spectroscopic investigations on sol-gel derived organic-inorganic hybrid films for photonics from ormosils and tetrapropylorthotitanate. Thin Solid Films 436:196-202

46. Gardin S, Signorini R, Pistore A, Della Giustina G, Brusatin G, Guglielmi M, Bozio R (2010) Photocatalytic performance of hybrid $\mathrm{SiO}_{2}-\mathrm{TiO}_{2}$ films. J Phys Chem C 114:7646-7652

47. Möls K, Aarik L, Mändar H, Kasikov A, Niilisk A, Rammula R, Aarik J (2019) Influence of phase composition on optical properties of $\mathrm{TiO}_{2}$ : Dependence of refractive index and band gap on formation of $\mathrm{TiO}_{2}$-II phase in thin films. Optical Mater 96:109335

48. Ohtani B, Ogawa Y, Nishimoto S-I (1997) Photocatalytic activity of amorphous-anatase mixture of titanium(IV) oxide particles suspended in aqueous solutions. J Phys Chem B 101:3746-3752

49. Jang HD, Kim S-K, Kim S-J (2001) Effect of particle size and phase composition of titanium dioxide nanoparticles on the photocatalytic properties. J Nanopart Res 3:141-147

50. Zhang Z, Maggard PA (2007) Investigation of photocatalyticallyactive hydrated forms of amorphous titania, $\mathrm{TiO}_{2} \cdot \mathrm{nH} 2 \mathrm{O}$. J Photochemistry Photobiol A 186:8-13 